\title{
INTEGRATED HIGHER EDUCATION INFORMATION SYSTEMS - PROFESSORS' KNOWLEDGE MANAGEMENT TOOL
}

\author{
Srečko Natek, International School for Social and Business Studies, Slovenia, srecko.natek@mfdps.si \\ Dušan Lesjak, University of Primorska and International School for Social and Business Studies, Slovenia, \\ dusan.lesjak@guest.arnes.si
}

\begin{abstract}
Higher education institutions (HEIs) are knowledge organisations, discovering, creating, capturing and sharing large amounts of knowledge. Therefore, the concept of their knowledge management is a very common view of their core activities. Higher education institutions' information systems (HEI IS) support different processes and provide users with appropriate data. It is not enough to design and implement HEI IS as the sum of educational, business and external information solutions; contemporary HEI IS are aimed to be fully integrated and capable of synergy exploitation. The main purpose of this paper is to study HEI IS integration as a professors' knowledge management tool. The starting point to fulfil the purpose of the paper is to design HEI IS functional architecture, where professors are important but only one of the groups of HEI IS users, involved in numerous higher education processes together with the higher education institution's services and students. The most important part of professors' work is capturing and sharing the knowledge, concentrated around their courses and their students. HEI IS solutions integration architecture and HEI IS data integration architecture play a vital role in improving professors' experience when preparing courses and teaching, and as such form a stable professors' knowledge management tool.
\end{abstract}

Keywords: Information System, Higher Education Information System, Higher Education Institution, Knowledge Management

\section{INTRODUCTION}

HEIs are knowledge organisations, discovering, creating, capturing and sharing large amounts of knowledge [2, 3, 4]. Therefore, the concept of their knowledge management is suitable for their core activities. Liebowitz stresses that knowledge combining data and business processes is valuable to any organisation and contributes to the overall strategic intelligence of HEIs and their success [5].

HEI's main activities include discovering, creating, capturing and sharing of knowledge, innovating education processes, educating students, motivating students for their personal development, preparing students for their careers and active responsible cooperation with their environments. Achieving these goals requires effective management supported by quality HEI IS.

HEI IS perform numerous processes and provide users with appropriate information. To ensure their effectiveness, they must be integrated with several information solutions (business solutions, external solutions, etc). It is not enough to design and implement HEI IS as the sum of their integrated parts. Contemporary HEI IS are aimed to be fully integrated and capable of synergy exploitation of their functionalities. So, one of HEI IS characteristics which significantly affects their efficiency and thus the efficiency of HEIs is their integration.

The rate of HEI IS integration is evaluated differently by different users. The main purpose of the paper is to research HEI IS integration as a professors' knowledge management tool. From HEI IS functional architecture (Figure 1) it is clear that professors are important but only one of the many groups of HEI IS users including services, students, etc. Professors are involved in numerous HEI's processes. Their work is related to the work of HEI's services and students including education, research and business activities and processes. 
The most important part of professors' work is dealing with knowledge one way or another. For them the HEI IS presents an important knowledge management tool, especially when creating, capturing and sharing the knowledge concentrated in their courses for and with their students.

Nonaka stresses that knowledge creation is a very complex process involving socialisation, externalization, combination and internationalisation with numerous participants using different solutions in different environments $[8,9]$. Thus, it is not trivial how HEI IS integrate different education and business information solutions (e.g. business applications, e-learning solutions, knowledge management solutions). In a well integrated HEI IS, professors can focus on preparing courses and teaching with maximum student interactions. In weakly integrated HEI IS, teachers work can often be described as partly administrative (e.g. entering data in different, not integrated applications). The aim of the paper is to discuss HEI IS integration as a professors' knowledge management tool.

\section{HEI IS FUNCTIONAL ARCHITECTURE}

Many authors have discussed information system (IS) architecture as a global model of an organisation's information system. Ward [11] understands IS architecture as a global model of an institution's IS which in a very concise manner describes the main parts of the IS and their mutual interdependence. Natek and Lesjak [7] adopt the previous definition from the methodological point of view as the description of IS architecture with a set of graphical models and their textual descriptions.

If we observe the IS from the users' point of view, functional architecture is not well understood or appreciated. Users are looking for usable functionalities when working with the IS. The paper focuses on integrated HEI IS as a professors' knowledge management tool. Therefore, designing functional architecture is the first step to understand professors' functional needs.

Basically, HEI IS functional architecture (Figure 1) identifies four types of internal users of HEI IS, who normally use and communicate with HEI IS through four HEI IS modules. On the left side of functional architecture, there are two important HEI's services, i.e. Education service and Student office. The Education service is mainly responsible for planning, preparing and monitoring educational processes. Curricula and schedules are the core of its activities in the Education planning HEI IS module [6]. The Student office is mainly responsible for educational processes. Students and operational educational processes are the core of its activities in the Education execution HEI IS module.

On the right side of HEI IS functional architecture (Figure 1), there are professors and students. Professors are responsible for the preparation and implementation of their courses. Teaching materials, education, student obligations, exams and communication with students are the core of their activities in the Professor HEI IS module. Students represent the largest group of HEI IS users. They are at the centre of HEI IS functional architecture. They are mainly responsible for completing their study obligations and gaining knowledge through the Student HEI IS module.

The lower part of HEI IS functional architecture shows the System HEI IS module, external information solutions and external institutions, connected and interacting with all HEI IS modules. The System HEI IS module is responsible for administering overall HEI's parameters, business information solutions for the information support of business processes, and external education solutions for implementing education in an e-environment as elearning, using specialised information solutions such as e-campus, Moodle, etc. External HEI IS users are normally institutions in the HEI IS environment, requesting reports and data about HEI's activities (e.g. libraries, external registration services, governments, statistics, universities, partners, etc.).

The HEI IS functional architecture model clearly shows all the relations which normally indicate user interactions and data flow inside and outside of HEI IS. The model shows that all HEI IS modules, users (internal and external) and information solutions (internal and external) are fully connected. If HEIs want to support teaching in a way that HEI IS will become a teachers' knowledge management tool, HEI IS must be fully integrated. It is not enough if 
Volume XII, No. 2, pp. 80-86, 2011

data is occasionally exported and imported from and to different information solutions. HEI IS must be integrated in several ways:

- by using the same databases from different solutions - the highest level of information integration,

- by sharing databases from different solutions by using database views, e.g. HEI IS use business data as a view over a business solutions database (Figures 2 and 3 ) - a high level of information integration,

- through automated, specific data export or import procedures, e.g. HEI IS export and import data to and from external e-learning solutions (Figures 2 and 3) - a normal level of information integration (e.g. CSV, XML files),

- through an occasional data export or import to or from external solutions - a weak level of information integration (e.g. CSV, XML files),

- through data being entered in each solution independently from other solutions - no information integration.

Higher levels of information solutions require HEI logical entity relationship data model. From the professors' point of view, higher levels of information integration are preferable as they save their time, otherwise spent on redundant data handling.

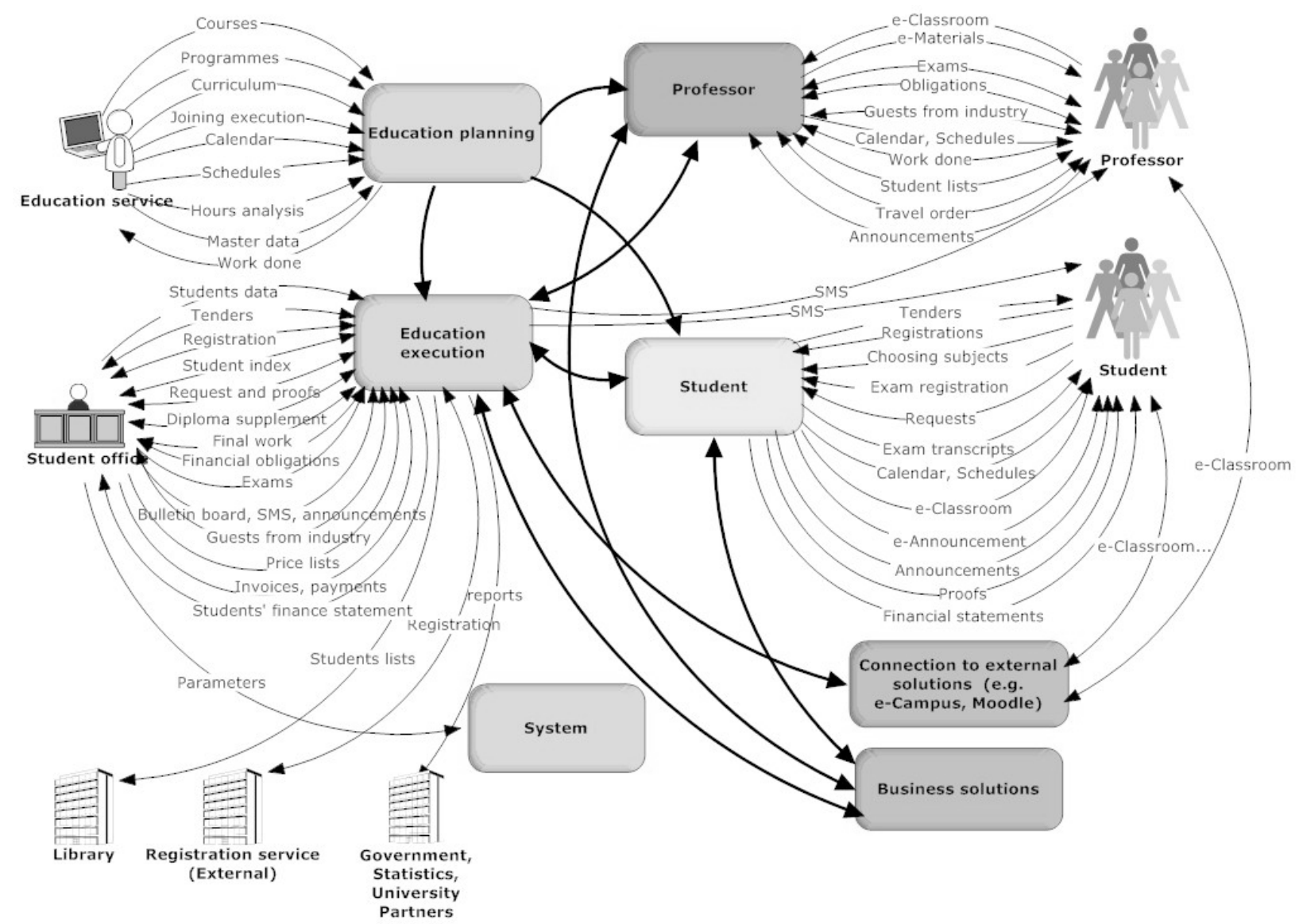

Figure 1. HEI IS functional architecture 
Volume XII, No. 2, pp. 80-86, 2011

\section{HEI IS SOLUTIONS AND DATA INTEGRATION ARCHITECTURE}

To establish the level of HEI IS integration, the functional architecture model is not precise enough. The answer is HEI IS solutions and data integration architecture models.

The HEI IS solutions integration architecture model (Figure 2) serves as an overview of solutions integration by observing all types of solutions interactions, connections and data flows.

The data aspect of solutions integration is always the most important. It is a very common approach that information models are complemented with data aspects (e.g. a global data model to complement a global process model), the special importance of which for the stability of IS is stressed by Adelman [1]. The HEI IS data integration architecture model (Figure 3) serves as a detailed model of data integration, normally investigating data integration methods between only two information solutions.

The centre of the HEI IS solutions integration architecture model (Figure 2) is the HEI IS solution (e.g. NOVIS, a higher education IS developed by a software company Nova Vizija [10]). The model describes the case where the HEI IS is integrated with the business solution and e-learning solution at different levels of information integration.

When entering or viewing business solutions data such as professors' data, HEI IS users use forms to enter the data and grids to view it which are part of the HEI IS. However, the data is physically not stored in the HEI IS database (DB). It is stored in the business solution DB but the HEI IS accesses it via Views and Synonym DB procedures. Such solutions ensure physical independence of both DB and at the same time ensure that the real data is stored only once. This is why they provide for strong information integration. 


\section{Volume XII, No. 2, pp. 63-, 2011}

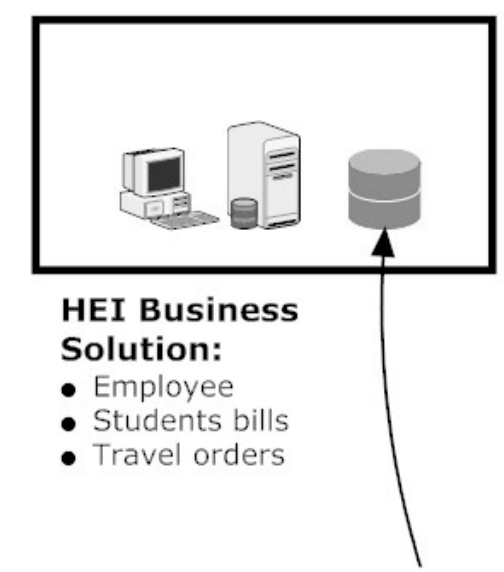

SQL Update/Select SQL Stored procedure Synonym DB procedure

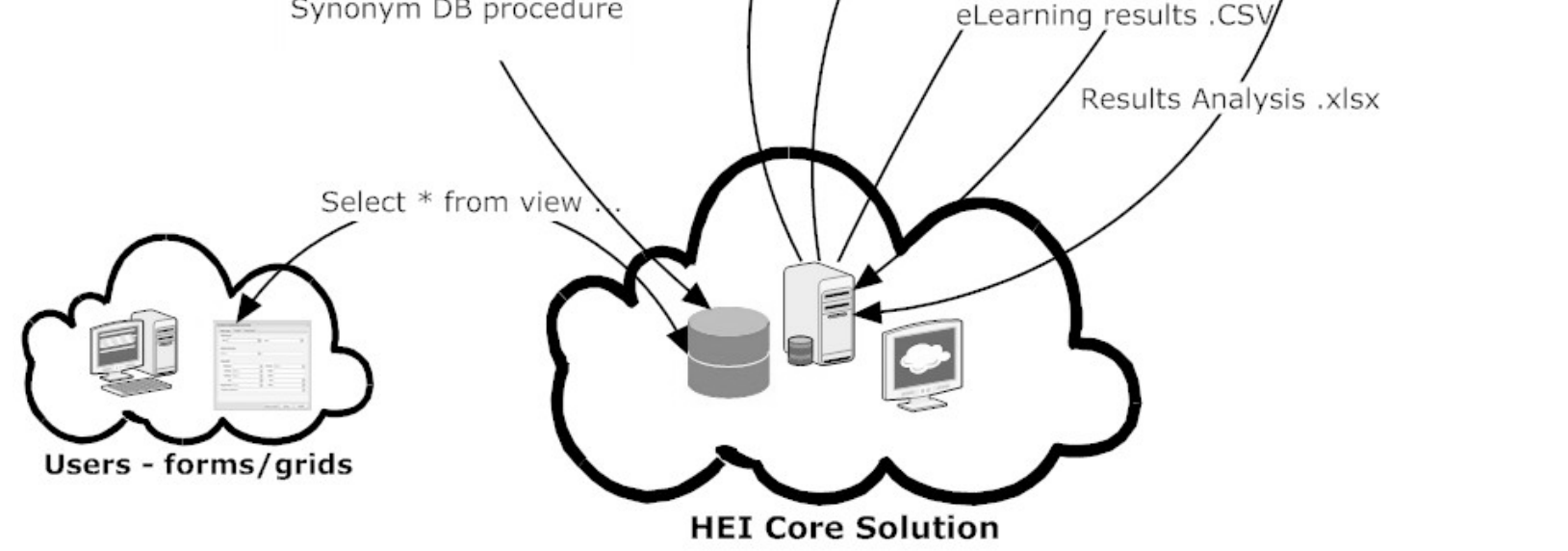

Figure 2. HEI IS solutions integration architecture

In case of external e-learning solutions HEI IS and e-learning solutions are normally integrated in the following ways:

- through automated specific export and import data between the HEI IS and e-learning solution via Comma Separated Value files format (.CSV), which ensures that professors have no administration about students registered for their online courses, and thus effectively manage their administrative knowledge about their students and their obligations,

- through a direct URL link for students to access external e-learning solutions directly from the HEI IS without having to sign-up separately to external e-learning solutions.

Figure 3 further describes detailed data integration methods, procedures and technology for evaluating the level of data integration in cases when HEI IS are integrated with e-learning solutions.

The models of HEI IS solutions and data integration architecture are efficient tools for evaluating HEI IS integration levels. 
Volume XII, No. 2, pp. 63-, 2011

HEI IS Solution
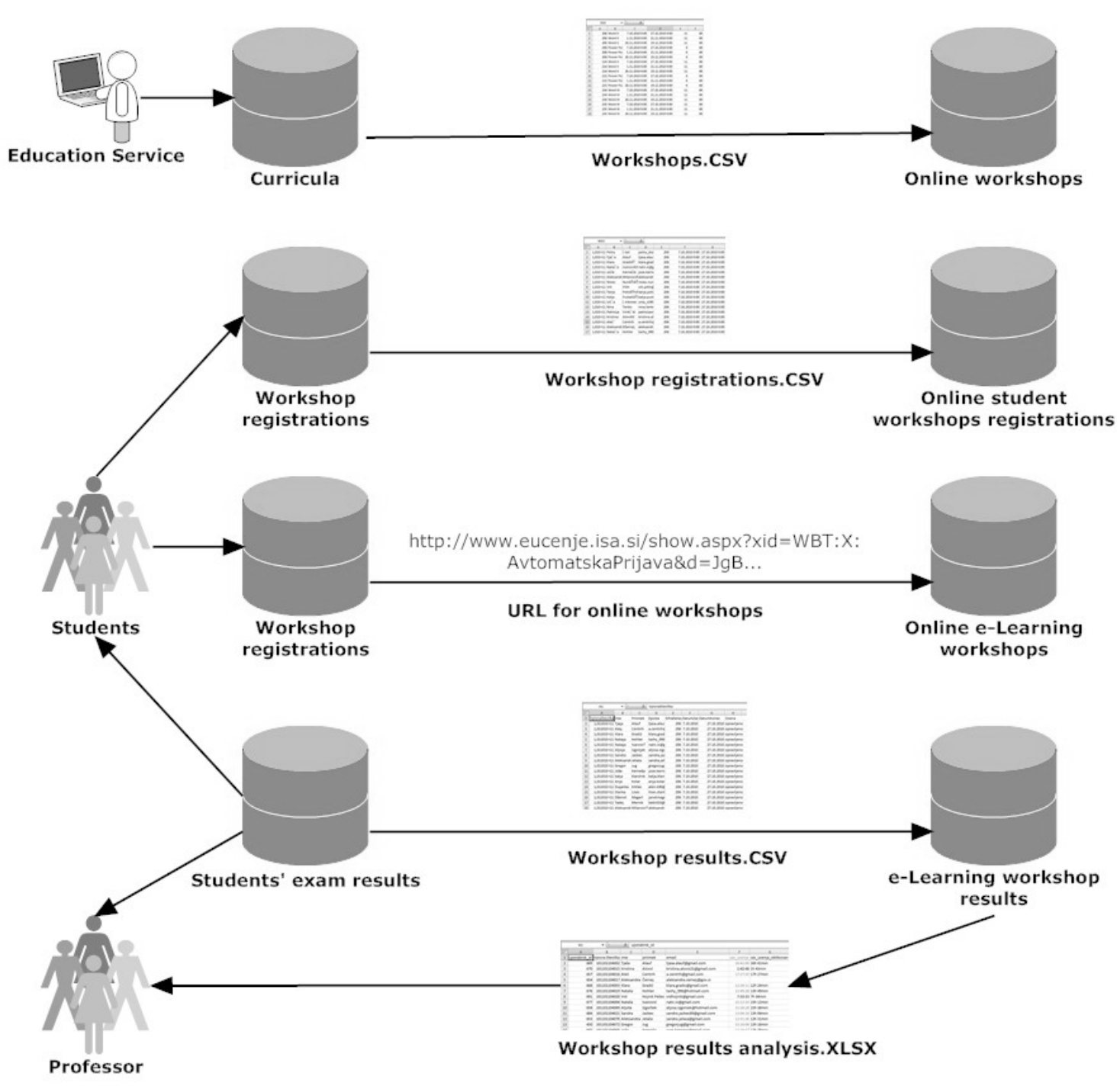

Figure 3. HEI IS data integration architecture

\section{INTEGRATED HEI IS - PROFESSORS’ KNOWLEDGE MANAGEMENT TOOL}

The majority of professors' work can be defined as discovering, capturing, sharing and application of knowledge. Thus, knowledge management plays a vital role in professors' day-to-day work. To achieve the efficiency and effectiveness of their work, professors are very interested in how to manage their and the institution's knowledge processes in their courses for their students.

Many existing HEI IS are described as being integrated and user-friendly (e.g. professors and students). However, professors are too often not part of designing and implementing the integration of HEI IS. Results of HEI IS integration are primarily measured from the technical point of view. The paper recognises the need to develop a HEI IS integration modelling technique where professors would be able to participate in the design and implementation 
Volume XII, No. 2, pp. 80-86, 2011

of HEI IS integration, since the way how HEI IS are integrated directly influences the ability of professors to manage their knowledge.

If HEI IS integration is implemented with care and with professors' knowledge management in mind, many professors' administrative and redundant tasks can be omitted. So, professors would be able to focus on their primary role of teaching students, whether face to face or in an e-environment.

For this purpose, the paper has developed functional, solution and data integration architecture to help professors fully participate in designing and implementing integrated HEI IS as their knowledge management tool.

\section{REFERENCES}

1. Adelman, S., Moss, L., Abai, M. (2005). Data strategy, Addison Wesley, 9.

2. Becerra-Fernandez, I., Gonzales, A., Sabherwal, R. (2004). Knowledge Management, Challenges, Solutions, and Technologies, Pearson Prentice Hall, 32.

3. Gappa, J. M., Austin, A., Trice, A. G. (2007). Rethinking Faculty work: Higher Education's Strategic Imperative, John Wiley \& Sons, Inc., 11.

4. Hislop, D. (2009). Knowledge Management in Organizations, Oxford University Press, $2^{\text {nd }}$ ed., 239-256.

5. Liebowitz, J. (2006). Strategic Intelligence, Business Intelligence, Competitive Intelligence, and Knowledge Management, Auerbach Publications, 22.

6. Mills, R. J., Hauser, K., Pratt, J. A. (2008). A Comprehensive two-level Framework for Information Systems Curriculum Design, Assessment and Improvement, Journal of Computer Information Systems, IACIS, XLVIII (4), 1-14.

7. Natek, S., Lesjak, D. (2010). The process architecture of information systems - higher education institution's managerial tool, Issues Inf. Syst., 2010, no. 1, vol. 11, p. 29-34.

8. Nonaka, I., Tekeuchi, H. (1995). The Knowledge-Creating Company, Oxford University Press, 71.

9. Nonaka, I., Toyama, R., Hirata, T. (2008). Managing Flow, A Process Theory of Knowledge-Based Firm, Palgrave Macmillan, 19.

10. Nova Vizija (2010). Novis, Visokošolski informacijski sistem. Nova Vizija.

11. Ward, J., Peppard J. (2002). Strategic Planning for Information Systems, $3^{\text {rd }}$ ed., Wiley, 192-204. 